\title{
Toddler milk perceptions and purchases: the role of Latino ethnicity
}

\author{
Emily W Duffy ${ }^{1}$, Lindsey Smith Taillie ${ }^{1}$, Ana Paula C Richter ${ }^{2}$, Isabella CA Higgins ${ }^{3}$, \\ Jennifer L Harris ${ }^{4}$ and Marissa G Hall $2,5, *$ \\ 'Department of Nutrition and Carolina Population Center, University of North Carolina at Chapel Hill Gillings School \\ of Global Public Health, Chapel Hill, NC, USA: 'Department of Health Behavior and Carolina Population Center, \\ University of North Carolina at Chapel Hill Gillings School of Global Public Health, 123 W. Franklin St., Suite 210, \\ Chapel Hill, NC 27516, USA: ${ }^{3}$ Carolina Population Center, University of North Carolina at Chapel Hill, Chapel Hill, \\ NC, USA: ${ }^{4}$ University of Connecticut Rudd Center for Food Policy \& Obesity, Hartford, CT, USA: ${ }^{\text {UNC Lineberger }}$ \\ Comprehensive Cancer Center, School of Medicine, CB \#7295, Chapel Hill, NC 27599, USA
}

Submitted 2 November 2020: Final revision received 7 January 2021: Accepted 18 January 2021: First published online 21 January 2021

\begin{abstract}
Objectives: Toddler milk (i.e. a nutrient-fortified milk-based drink marketed for children 12-36 months old) is increasingly being marketed in the USA despite not being recommended for young children. There is evidence of targeted toddler milk marketing to Latinos in the USA. This study aimed to explore toddler milk perceptions and behaviours among Latino and non-Latino parents.

Design: An online survey assessed toddler milk perceptions, behaviours and interpretations of nutrition-related claims. Multivariable logistic and linear regression explored socio-demographic correlates of parent reported past purchases and perceived healthfulness.

Setting: Online.

Participants: National convenience sample of 1078 US parents of children aged 2-12 years (48\% Latino).

Results: About half of parents (51\%) had previously purchased toddler milk and few (11\%) perceived toddler milk as unhealthy. Latino parents were more likely to have purchased toddler milk than non-Latino parents $(P<0 \cdot 001)$, but there were no differences in perceived product healthfulness $(P=0 \cdot 47)$. Compared to parents born in the USA, parents living in the USA 10 years or less were more likely to have purchased toddler milk $(P<0.001)$ and perceive toddler milk as healthier $(P=0.002)$. Open-ended interpretations of claims were primarily positive, suggesting 'health halo' effects.

Conclusions: Common misperceptions about toddler milk healthfulness suggest stronger labelling regulations are needed. Greater reported purchases by Latino parents and recent immigrants warrant further investigation.
\end{abstract}

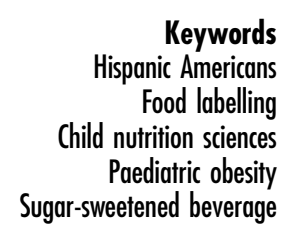

Diet quality often declines throughout early childhood as the child transitions from breast-feeding or infant formula to complementary foods and then to family foods ${ }^{(1-3)}$. Poor diet quality in early childhood has been associated with worse dietary behaviours and obesity risk later in childhood $^{(4-6)}$. Compared to non-Latino White children, young Latino children are more likely to have obesity and worse diet quality, including higher consumption of infant formula, juice and sugary drinks ${ }^{(7-9)}$. Preliminary research suggests that consumption of toddler milk (i.e. nutrient-fortified milk-based drinks marketed for children 12-36 months old that typically contain added sugar) may be an emerging issue in early childhood diet quality, particularly among Latino children ${ }^{(10,11)}$. In a recent survey, $60 \%$ of parents stated they believed toddler milk provided nutrients that could not be obtained from other foods and beverages ${ }^{(10)}$. This study also found that Latino parents were more likely to have served toddler milk in the last month than non-Latino White parents ${ }^{(10)}$. However, further research is needed to understand why parents may be providing toddler milk to their children. 
The American Academy of Pediatrics and other major nutrition and health organisations recommend against the consumption of toddler milk because it can interfere with sustained breast-feeding, often contains added sugar and provides no unique nutritional value beyond what an adequate diet would provide ${ }^{(12)}$. Available evidence in the USA indicates that parents may not be aware of these recommendations and many believe toddler milk is healthy ${ }^{(10,13)}$. Among Latino parents, preliminary studies suggest favourable toddler milk perceptions may be influenced by targeted marketing by formula companies, misleading nutrition-related claims on the product packaging or cultural norms related to toddler milk $\mathrm{k}^{(10,11)}$. One study also identified differences in toddler milk provision between primarily English-speaking and primarily Spanish-speaking Latino parents ${ }^{(10)}$. This is an important finding given other studies have identified differences in child feeding behaviours and dietary behaviours more generally by level of acculturation ${ }^{(14-17)}$.To inform public health nutrition interventions and policies to reduce toddler milk consumption, more research is needed to better understand what types of parental characteristics, including Latino ethnicity and acculturation, are associated with favourable perceptions of and purchases of toddler milk.

To that end, this study aimed to explore why parents may be providing toddler milk to their children among Latino and non-Latino parents, describe parent interpretations of claims on toddler milk, and explore correlates of perceived toddler milk healthfulness and past purchases.

\section{Methods}

\section{Participants}

In October 2019, we recruited an online convenience sample using a survey research platform, CloudResearch Prime Panels, as part of a separate experiment examining the impact of warning designs on sugary drink perceptions among Latino and non-Latino parents. The study procedures have been reported elsewhere. The panel company used purposive sampling to obtain a sample with roughly half Latinos and half non-Latinos. Participants were eligible if they were currently residing in the USA, at least 18 years old, and had at least one child between 2 and 12 years old. Participants had the option to complete the survey in English or Spanish.

\section{Procedures}

All study participants provided written informed consent. Participants completed an online survey programmed into Qualtrics survey software. After answering questions about the warnings experiment, participants answered questions related to toddler milk. Upon completion of the survey, participants received incentives in cash, gift cards or reward points from Prime Panels. Prior to data collection, the study was pre-registered on AsPredicted.org: https://aspredicted. org/bw59b.pdf.

\section{Measures}

Participants were first shown images of two toddler milk varieties (Nido Kinder $1+$ and Enfagrow Toddler Next Step) and the survey displayed a definition of toddler milk that stated toddler milks 'are intended for children at least 12 months old and are different from formulas like Enfamil and Similac that are for babies younger than 12 months old' to minimise confusion with infant formula (exact item wording for all measures appears in online supplementary material, Supplemental Table 1). We selected these brands because prior research has shown they are heavily advertised on Spanish-language $\mathrm{TV}^{(11)}$.

\section{Demographic measures}

Latino ethnicity was assessed using self-report with an item from the US Census ${ }^{(18)}$ : 'Are you of Hispanic, Latino, or Spanish origin?', coded as 'yes' or 'no'. Latino ethnicity in our analyses is not an indicator of biological differences but is a representation of the sociopolitical processes that differentially impact individuals in the USA based on ethnicity. We also examined years living in the USA as a measure of acculturation because diet and other health behaviours have been shown to change over time in the USA among Latino immigrants ${ }^{(17)}$. Participants were asked how many years they had lived in the USA, and we recoded responses into three categories (born in the USA, lived in the USA more than 10 years or lived in the USA 10 years or less) based on the distribution in our sample. Parent and child sugary drink consumption were assessed using items adapted from previously validated measures $^{(19,20)}$. All other demographic variables were assessed via self-report.

\section{Toddler milk perceptions and behaviours measures}

The survey then assessed familiarity with toddler milk (defined as ever seeing toddler milk in a store), purchases of toddler milk, reasons for purchasing toddler milk, perceived toddler milk healthfulness ${ }^{(21)}$ and healthfulness compared to regular milk (comparative healthfulness). The primary outcome was perceived healthfulness of toddler milk, which was assessed with one item 'How healthy or unhealthy would it be for a toddler to drink this beverage every day?' with a five-point Likert-style response scale, adapted from a prior study ${ }^{(21)}$. Finally, participants were shown an image of Nido Kinder 1+, and open-ended responses assessed parent interpretations of two claims ('Helps Support Healthy Growth' and 'Immunity') on the Nido Kinder 1+ package. We selected these claims because they are two predominant claims on the front of the package.

\section{Analysis}

Our analytic sample included 1078 parents. We first ran descriptive statistics for survey items that assessed toddler 
milk familiarity, purchases, reasons for purchase, perceived healthfulness and comparative healthfulness. For the open-ended claim responses, we developed a codebook to quantitatively code all open-ended responses into themes. Prior to coding, a fluent Spanish speaker (AR) translated all Spanish open-ended responses to English. We iteratively revised the codebook after an initial round of coding $5 \%$ of responses. Three coders (ED, IH and AR) divided and double-coded all responses. We resolved all coding discrepancies by consensus.

We used multivariable logistic regression to evaluate the associations between whether the participant had ever purchased toddler milk and Latino ethnicity, years living in the USA, parent sugary drink consumption, child sugary drink consumption, parent age, gender, use of the Supplemental Nutrition Assistance Program (SNAP) in the last year, education, BMI, annual household income and presence of children 3 years old or younger in the household. We used Stata's margins command to calculate and compare the predicted probabilities of having ever purchased toddler milk for each covariate. This logistic regression analysis was exploratory and not included in the pre-registration.

We also examined predictors of perceived toddler milk healthfulness using multivariable linear regression. The model included the same set of covariates as the logistic regression model. There were no indications of multicollinearity, although residuals appeared skewed based on Shapiro-Wilk test, so we also ran an ordinal logistic regression model. The same covariates were statistically significant in the linear and ordinal models, so we retained the linear model for ease of interpretation.

We conducted sensitivity analyses to determine if exposure to different stimuli in previous parts of the survey (questions not related to toddler milks) affected perceived healthfulness of toddler milk. None of the experimental arms were associated with the outcome $(P>0 \cdot 10)$, and the patterns of the direction of effect and statistical significance of the other predictors in the model remained the same, so we retained the model without group assignment. Additionally, to better understand the role of acculturation among Latino populations specifically, we conducted sensitivity analyses to limit the years in the US variable to only Latino participants (29 participants excluded from analyses). The patterns of the direction of effect and statistical significance of all predictors in the model remained the same with the exception of healthy weight or underweight which became a significant predictor of purchases in the logistic regression. We retained the original years in the US variable to maintain a larger sample size. Adjusted models used complete case analyses to handle missing data, dropping cases with missing data on any of the variables included in the model.

All analyses were conducted using STATA version 16.1, with two-tailed tests and a critical alpha of 0.05 .

\section{Results}

\section{Demographic characteristics}

The mean age of participants was 35.3 years (Table 1 ). About one-third ( $35 \%$ ) had a child 3 years old or younger in the household. Slightly more than half of the participants (58\%) were female and $48 \%$ of participants identified as Latino or Hispanic. Most participants (78\%) were born in the USA, $15 \%$ were not born in the USA and had lived in the USA more than 10 years, and $7 \%$ were not born in the USA and had lived in the USA for 10 years or less. Almost all immigrants who had lived in the USA more than 10 years $(85 \%)$ and those who had lived in the USA 10 years or less $(92 \%)$ were Latino. About half of participants had a high school degree or less (48\%). Similarly, about half ( $47 \%$ ) of participants had an annual household income of less than $\$ 50000$, and $32 \%$ used SNAP in the last year. About two-thirds (61\%) of parents were either overweight or had obesity. Most participants (74\%) and their children ( $72 \%$ ) consumed sugary drinks at least once a week. Most participants completed the survey in English (86\%).

\section{Toddler milk familiarity and purchases}

Most parents (79\%) were familiar with toddler milk (i.e. had seen it in a store) (Table 1). About half of parents (51\%) had previously purchased toddler milk, and about one-quarter (23\%) had purchased it ten or more times (Table 1). Among parents who had purchased toddler milk, the most common reasons for purchasing included to provide vitamins and nutrients (57\%), to support growth ( $51 \%$ ) and brain development (38\%), because toddler milk is healthy (32\%), and because their child liked the taste (25\%) (Fig. 1). Parents' perceptions of why they thought other parents would provide toddler milk to their children were similar to their own reasons for purchasing (Fig. 1).

In adjusted analyses, Latino parents were more likely (predicted probability $=59 \%$ ) to have ever purchased toddler milk compared to non-Latino parents (43\%) $(P<0.001)$ (Table 2). Compared to parents born in the USA ( $48 \%$ ), parents who had lived in the USA 10 years or less were also more likely (73\%) to have purchased toddler milk $(P<0 \cdot 001)$. There was no difference between parents born in the USA and parents who had lived in the USA more than 10 years $(51 \%)(P=0.656)$. Other factors associated with greater likelihood of purchasing toddler milk were greater sugary drink consumption among both the parent and the child, being male, and having at least a 4-year college degree (all $P<0.05$ ). Older parents ( 40 year or older) were less likely to have purchased toddler milk than parents aged 18-29 years $(P=0.004)$. There were no differences in the likelihood of purchasing toddler milk by household income $(P=0.608)$. 
Table 1 Participant demographic characteristics

\begin{tabular}{|c|c|c|}
\hline & $n 1078$ & $\%$ \\
\hline \multicolumn{3}{|l|}{ Age } \\
\hline $18-29$ years & 238 & 22 \\
\hline $30-39$ years & 563 & 52 \\
\hline $40-54$ years & 259 & 24 \\
\hline $55+$ years & 15 & \\
\hline Mean & \multicolumn{2}{|l|}{$35 \cdot 3$} \\
\hline SD & \multicolumn{2}{|l|}{$7 \cdot 4$} \\
\hline \multicolumn{3}{|l|}{ Gender } \\
\hline Male & 445 & 41 \\
\hline Female & 628 & 58 \\
\hline Transgender or other & 5 & 0 \\
\hline Latino ethnicity & 514 & 48 \\
\hline \multicolumn{3}{|l|}{ Race } \\
\hline White & 796 & 74 \\
\hline Black or African American & 135 & 13 \\
\hline Asian & 23 & 2 \\
\hline American Indian or Alaska Native & 1 & 0 \\
\hline Pacific Islander & 2 & 0 \\
\hline Other or multiracial & 121 & 11 \\
\hline \multicolumn{3}{|l|}{ Years in the USA } \\
\hline Born in the USA & 845 & 78 \\
\hline More than 10 years in the USA & 158 & 15 \\
\hline 10 years or less in the USA & 74 & 7 \\
\hline \multicolumn{3}{|l|}{ Educational attainment } \\
\hline Less than high school degree & 39 & 4 \\
\hline High school degree & 473 & 44 \\
\hline Four-year college degree & 428 & 40 \\
\hline Graduate degree & 138 & 13 \\
\hline \multicolumn{3}{|l|}{ Household Income } \\
\hline$\$ 0-\$ 24999$ & 213 & 20 \\
\hline$\$ 25000-\$ 49999$ & 288 & 27 \\
\hline$\$ 50000-\$ 74999$ & 202 & 19 \\
\hline$\$ 75000+$ & 375 & 35 \\
\hline Used SNAP in the last year & 344 & 32 \\
\hline \multicolumn{3}{|l|}{ Number of children in household (0-18 years) } \\
\hline 1 & 381 & 35 \\
\hline 2 & 416 & 39 \\
\hline 3 & 184 & 17 \\
\hline 4 or more & 97 & 9 \\
\hline $\begin{array}{l}\text { Young children ( } 0-3 \text { years) in household } \\
\text { BMI }\end{array}$ & 374 & 35 \\
\hline Underweight $(<18.5)$ & 37 & 3 \\
\hline Healthy weight (18.5-24.9) & 384 & 36 \\
\hline Overweight (25.0-29.9) & 327 & 31 \\
\hline Obese (30 or above) & 314 & 30 \\
\hline \multicolumn{3}{|l|}{ Frequency of sugary drink consumption } \\
\hline 0 to 1 times per week & 279 & 26 \\
\hline$>1$ to $<7$ times per week & 370 & 34 \\
\hline 1 to 2 times per day & 205 & 19 \\
\hline More than 2 times per day & 224 & 21 \\
\hline \multicolumn{3}{|c|}{ Child's frequency of sugary drink consumption* } \\
\hline 0 to 1 times per week & 300 & 28 \\
\hline$>1$ to $<7$ times per week & 425 & 39 \\
\hline 1 to 2 times per day & 189 & 18 \\
\hline More than 2 times per day & 164 & 15 \\
\hline \multicolumn{3}{|l|}{ Language of survey administration } \\
\hline English & 924 & 86 \\
\hline Spanish & 154 & 14 \\
\hline & 852 & 79 \\
\hline \multicolumn{3}{|l|}{ Number of times purchased toddler milk } \\
\hline 0 times & 528 & 49 \\
\hline $1-2$ times & 107 & 10 \\
\hline 3-4 times & 107 & 10 \\
\hline $5-9$ times & 83 & 8 \\
\hline 10 or more times & 252 & 23 \\
\hline
\end{tabular}

SNAP: Supplemental Nutrition Assistance Program

${ }^{*}$ Asked about one child aged $2-12$ years with the most recent birthday.

\section{Comparative and perceived healthfulness of toddler milk}

Most parents said that toddler milk was as healthy (38\%) as or healthier (44\%) than regular milk (i.e. comparative healthfulness). Similarly, when asked how healthy it would be for a toddler to consume toddler milk every day (i.e. perceived healthfulness), more than half of parents (57\%) reported this would be healthy ( 4 or 5 on Likert scale). In multivariable regression, Latino ethnicity was not associated with perceived healthfulness (Table 3). Parents who had lived in the USA 10 or fewer years perceived toddler milk as healthier compared to parents born in the USA ( $\beta=0.41, P=0.002)$. Other factors associated with greater perceived healthfulness were using SNAP in the last year $(\beta=0 \cdot 18, P=0.02)$, greater parent sugary drink consumption $(\beta=0.32, P<0.001)$ and greater child sugary drink consumption $(\beta=0.31, P<0.001)$.

\section{Interpretations of product claims}

When asked to interpret the claim 'Helps Support Healthy Growth', parents' open-ended responses were most often directly related to growth (34\%) (Table 4). Some parents had broader interpretations of this claim such as thinking that the claim meant toddler milk contained vitamins, minerals or other nutrients $(32 \%)$ or that toddler milk was healthy or good for children (13\%). In interpreting the claim 'Immunity', most parents (61\%) stated this claim meant toddler milk prevented illness or boosted the immune system. Some parents (10\%) stated the immunity claim meant toddler milk contained vitamins, minerals or other nutrients that support the immune system. Few parents stated that the claims were misleading or expressed scepticism about the claims ( $2 \%$ of healthy growth and $1 \%$ of immunity responses).

\section{Discussion}

This study adds to the growing body of evidence suggesting toddler milk may be an emerging public health nutrition concern in the USA, particularly in Latino communities. Despite recommendations from the American Academy of Pediatrics and other national health organisations against toddler milk consumption, more than half of parents in our study stated it would be healthy for a toddler to drink toddler milk every day ( 4 or 5 on perceived healthfulness item). This is consistent with findings from other studies which have demonstrated many parents believe toddler milk is healthy ${ }^{(10,13)}$. Additionally, most parents thought toddler milk was as healthy as or healthier than regular milk. This finding is concerning as toddler milk often contains added sugars and can be more than four times the cost of an equivalent amount of regular milk ${ }^{(12)}$. 


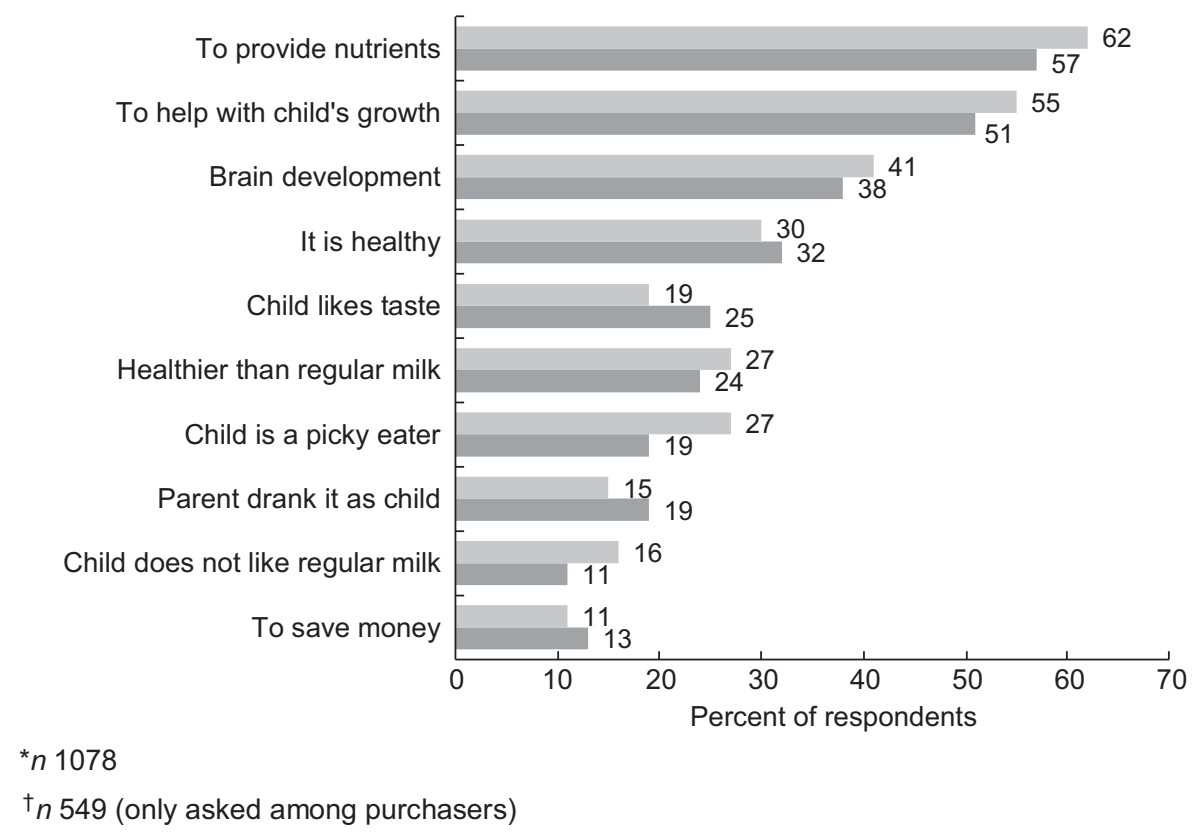

Fig. 1 Reasons parents reported they purchased toddler milk and that other parents would purchase toddler milk. $₫$ Other parents*; personal†

Future studies should explore whether parents are using toddler milk as a replacement for regular milk given the high prevalence of misperceptions about the comparative healthfulness of toddler milk and regular milk in our sample.

In our study, Latino ethnicity was associated with a greater likelihood of having purchased toddler milk, but not with greater perceived healthfulness of toddler milk. We also found that participants who had lived in the USA 10 years or less were more likely to have purchased toddler milk and had greater perceived healthfulness compared to participants born in the USA. Only one other study has examined the role of Latino ethnicity and acculturation in toddler milk provision and found that primarily Englishspeaking Latino parents were slightly more likely to report providing toddler milk than primarily Spanish-speaking Latino parents, and Latino parents were more likely to report providing toddler milk than non-Latino parents ${ }^{(10)}$. Given evidence of targeted marketing of toddler milk to Latinos through advertisements on Spanish-language $\mathrm{TV}^{(11)}$ and use of Spanish language on toddler milk packaging $^{(22)}$, as well as documented disparities in diet quality and obesity among Latino children, taken together, these findings are cause for concern. It is possible that toddler milk may be displacing more nutrient-dense foods and contributing to sweet taste preferences given the added sugar content ${ }^{(12)}$. However, more research is needed using nationally representative samples to understand if there are ethnicity-based disparities in toddler milk consumption, the impact of toddler milk consumption on overall diet quality, what role acculturation may play in toddler milk consumption and if these relationships differ based on parents' level of education or other socio-demographic characteristics.
Additionally, we found in the regression analyses greater parent and child sugary drink consumption were associated with greater perceived healthfulness and greater likelihood of purchasing toddler milk. This may be an indicator of toddler milk contributing to sweet taste preferences in early childhood ${ }^{(23)}$, but directionality cannot be established. Sugary drink reduction efforts should consider including information about toddler milk recommendations in early childhood. Parents who had participated in SNAP in the last year also had greater perceived healthfulness of toddler milk. Finally, we found more highly educated parents were more likely to have purchased toddler milk, which is consistent with prior research ${ }^{(10,13)}$. No research has explored why more educated parents may be more likely to purchase toddler milk. More educated parents may be more likely to look for alternatives to regular milk, use nutrition-related claims in toddler milk purchasing decisions ${ }^{(24,25)}$ or have more favourable interpretations of these claims ${ }^{(13)}$, but this should be examined in future studies.

Our findings also suggest that parents extended the meaning of toddler milk claims as a statement about the overall healthfulness of the product, a phenomenon known as a 'health halo' effect ${ }^{(26)}$. For instance, parents' interpretations of the claim 'Helps Support Healthy Growth' demonstrated the 'health halo' effect when parents mentioned benefits like vitamin content or brain development that were not included in the claim. This finding is in line with prior studies that have explored parent perceptions of toddler milk claims ${ }^{(10,13)}$. For example, one study asked parents to indicate what various messages on a toddler milk package told them about the product and responses included giving toddlers nutrition they would 
Table 2 Differences in predicted probability of having ever purchased toddler milk among demographic groups ( $n$ 1051†)

\begin{tabular}{|c|c|c|}
\hline & $\begin{array}{c}\text { Predicted } \\
\text { probability (\%) }\end{array}$ & $P$ \\
\hline \multicolumn{3}{|l|}{ Ethnicity } \\
\hline Non-Latino (ref) & 43 & \\
\hline Latino & $59^{*}$ & $<0.001^{*}$ \\
\hline \multicolumn{3}{|l|}{ Years in the USA } \\
\hline Born in the USA (ref) & 48 & \\
\hline More than 10 years in the USA & 51 & 0.656 \\
\hline 10 years or less in the USA & $73^{*}$ & $<0.001^{*}$ \\
\hline \multicolumn{3}{|l|}{ Parent sugary drink consumption } \\
\hline Less than 7 times per week (ref) & 45 & \\
\hline 7 or more times per week & $59^{*}$ & $<0.001^{*}$ \\
\hline \multicolumn{3}{|l|}{ Child sugary drink consumption $\ddagger$} \\
\hline Less than 7 times per week (ref) & 47 & \\
\hline 7 or more times per week & $57^{*}$ & $0.025^{*}$ \\
\hline \multicolumn{3}{|l|}{ Age } \\
\hline $18-29$ years (ref) & 57 & \\
\hline 30-39 years & 51 & $0 \cdot 181$ \\
\hline $40+$ years & $42^{*}$ & $0.004^{*}$ \\
\hline \multicolumn{3}{|l|}{ Gender§ } \\
\hline Woman (ref) & 45 & \\
\hline Man & $58^{\star}$ & $<0.001^{*}$ \\
\hline \multicolumn{3}{|l|}{ Used SNAP in the last year } \\
\hline No (ref) & 48 & \\
\hline Yes & 55 & 0.084 \\
\hline \multicolumn{3}{|l|}{ Education } \\
\hline High school graduate or less (ref) & 41 & \\
\hline \multirow{2}{*}{\multicolumn{3}{|c|}{ BMI }} \\
\hline & & \\
\hline Overweight or obese (ref) & 48 & \\
\hline Underweight or healthy weight & 54 & 0.054 \\
\hline \multicolumn{3}{|l|}{ Annual household income } \\
\hline Less than $\$ 50000$ (ref) & 49 & \\
\hline$\$ 50000$ or more & 51 & 0.608 \\
\hline \multicolumn{3}{|l|}{$\begin{array}{l}\text { Young children ( } 0-3 \text { years) in } \\
\text { household }\end{array}$} \\
\hline No (ref) & 49 & \\
\hline Yes & 53 & 0.247 \\
\hline
\end{tabular}

SNAP: Supplemental Nutrition Assistance Program.

*Predicted probabilities are statistically significantly different at an alpha of 0.05 . †Missing BMI data from sixteen participants, age data from three, Latino ethnicity data from one, years in the USA data from one, SNAP data from one and past purchase data from one.

‡Asked about one child aged 2-12 years with the most recent birthday.

$\S$ Transgender participants were excluded from analyses due to small sample size $(n 5)$.

not get from other sources, being necessary for toddlers to have correct nutrition, and being better for toddlers than regular milk, none of which were included in the claims ${ }^{(13)}$. Moreover, when asked to state what two claims told them about toddler milk, few parents in our sample expressed scepticism about the claims or thought the claims were misleading. Future studies should use experimental methods to examine the causal impact of toddler milk claims on parent purchase behaviours.

Many of the claims on toddler milk are considered structure/function claims by the US Food and Drug Administration (FDA). FDA does not require premarket approval of structure/function claims on food products nor that these claims be substantiated by scientific evidence $^{(27)}$. Additionally, the claims on some toddler milk
Table 3 Correlates of perceived healthfulness of toddler milk (n 1052†)

\begin{tabular}{|c|c|c|c|c|}
\hline & Mean & $\beta$ & SE & $P$ \\
\hline \multicolumn{5}{|l|}{ Ethnicity } \\
\hline Non-Latino (ref) & 3.63 & & & \\
\hline Latino & 3.71 & 0.05 & 0.07 & 0.47 \\
\hline \multicolumn{5}{|l|}{ Years in the USA } \\
\hline Born in the USA (ref) & 3.65 & & & \\
\hline More than 10 years in the USA & 3.70 & $0 \cdot 12$ & 0.10 & 0.24 \\
\hline 10 years or less in the USA & $3 \cdot 85^{\star}$ & $0.41^{*}$ & $0 \cdot 13^{*}$ & $0.002^{*}$ \\
\hline \multicolumn{5}{|l|}{ Parent sugary drink consumption } \\
\hline $\begin{array}{l}\text { Less than } 7 \text { times per week } \\
\text { (ref) }\end{array}$ & 3.46 & & & \\
\hline 7 or more times per week & $3 \cdot 98^{\star}$ & $0.32^{*}$ & $0.08^{\star}$ & $<0.001^{*}$ \\
\hline \multicolumn{5}{|l|}{ Child sugary drink consumption $\ddagger$} \\
\hline $\begin{array}{l}\text { Less than } 7 \text { times per week } \\
\text { (ref) }\end{array}$ & 3.50 & & & \\
\hline 7 or more times per week & $4.03^{*}$ & $0 \cdot 31^{*}$ & $0.08^{*}$ & $<0.001^{*}$ \\
\hline \multicolumn{5}{|l|}{ Age } \\
\hline $18-29$ years (ref) & 3.65 & & & \\
\hline $30-39$ years & 3.74 & 0.08 & 0.08 & 0.33 \\
\hline $40+$ years & 3.56 & -0.06 & $0 \cdot 10$ & 0.52 \\
\hline \multicolumn{5}{|l|}{ Gender§ } \\
\hline Woman (ref) & $3 \cdot 61$ & & & \\
\hline Man & 3.75 & 0.09 & 0.07 & 0.21 \\
\hline \multicolumn{5}{|l|}{ Used SNAP in the last year } \\
\hline No (ref) & 3.59 & & & \\
\hline Yes & $3 \cdot 83^{*}$ & $0 \cdot 18^{*}$ & $0.07^{*}$ & $0 \cdot 02^{*}$ \\
\hline \multicolumn{5}{|l|}{ Education } \\
\hline $\begin{array}{l}\text { High school graduate or less } \\
\text { (ref) }\end{array}$ & $3 \cdot 62$ & & & \\
\hline \multicolumn{5}{|c|}{ BMI } \\
\hline Overweight or obese (ref) & 3.60 & & & \\
\hline Underweight or healthy weight & 3.75 & 0.09 & 0.07 & 0.15 \\
\hline \multicolumn{5}{|l|}{ Annual household income } \\
\hline Less than $\$ 50000$ (ref) & 3.63 & & & \\
\hline$\$ 50000$ or more & 3.71 & 0.09 & 0.07 & 0.26 \\
\hline \multicolumn{5}{|l|}{$\begin{array}{l}\text { Young children ( } 0-3 \text { years) in } \\
\text { household }\end{array}$} \\
\hline No (ref) & 3.68 & & & \\
\hline Yes & 3.65 & 0.03 & 0.07 & 0.69 \\
\hline
\end{tabular}

SNAP: Supplemental Nutrition Assistance Program.

*Statistically significant at an alpha of 0.05 .

tMissing BMI data from sixteen participants, age data from three, Latino ethnicity data from one, years in the US data from one, SNAP data from one.

$\ddagger$ Asked about one child aged 2-12 years with the most recent birthday.

$\S T$ Transgender participants were excluded from analyses due to small sample size $(n 5)$.

products are present in English and Spanish (as well as other product information), further evidence of targeted marketing by formula companies to Latino communities ${ }^{(22)}$. Experts have called for stricter regulations of these claims within FDA and for Congressional, Federal Trade Commission (FTC), or other government agency actions to prevent other forms of misleading toddler milk marketing ${ }^{(28-31)}$. Our findings provide initial evidence that these stricter regulations may be warranted. For example, the FDA could establish a regulatory structure that specifically applies to products intended for young children or infant formula manufacturers with contracts with the Special Supplemental Nutrition Program for Women, Infants, and Children could be required to comply with the WHO International Code of Marketing of Breast-Milk 


\section{Public Health Nutrition}

Table 4 Prevalence of themes identified in open-ended parent interpretations of two claims ('Helps Support Healthy Growth' and 'Immunity') on Nido Kinder 1+ toddler milk packaging

\begin{tabular}{|c|c|c|c|c|c|c|}
\hline \multirow[b]{2}{*}{ Theme } & \multirow[b]{2}{*}{ Description } & \multirow[b]{2}{*}{ Exemplary quotes } & \multicolumn{2}{|c|}{$\begin{array}{c}\text { Prevalence of theme in } \\
\text { healthy growth responses }\end{array}$} & \multicolumn{2}{|c|}{$\begin{array}{l}\text { Prevalence of theme in } \\
\text { immunity responsest }\end{array}$} \\
\hline & & & $n$ & $\%$ & $n$ & $\%$ \\
\hline Growth & $\begin{array}{l}\text { Reference to the words grow, growth or growing } \\
\text { or more general references to getting bigger, } \\
\text { stronger or taller }\end{array}$ & $\begin{array}{l}\text { It helps reinforce growth. (hg) Make kids grow strong } \\
\text { and tall and healthy. (hg) }\end{array}$ & 370 & 34 & 16 & 1 \\
\hline $\begin{array}{l}\text { Vitamins, minerals and } \\
\text { nutrients }\end{array}$ & $\begin{array}{l}\text { Reference to the product containing nutrients, } \\
\text { vitamins or minerals }\end{array}$ & $\begin{array}{l}\text { Has special vitamins to nourish growth. (hg) That it } \\
\text { has vitamins that help them to not get sick. (i) }\end{array}$ & 344 & 32 & 109 & 10 \\
\hline $\begin{array}{l}\text { General health } \\
\text { promotion }\end{array}$ & $\begin{array}{l}\text { Reference to the product being healthy, } \\
\text { promoting health or being good for you or for } \\
\text { children }\end{array}$ & $\begin{array}{l}\text { It is good for children. (hg) It is very healthy for } \\
\text { child. (i) }\end{array}$ & 138 & 13 & 79 & 7 \\
\hline $\begin{array}{l}\text { Positive perception } \\
\text { (non-health-related) }\end{array}$ & $\begin{array}{l}\text { Reference about the product quality, generally } \\
\text { liking the product or other positive perceptions }\end{array}$ & It is a good product. (hg) It is safe for kids. (i) & 74 & 7 & 60 & 6 \\
\hline General development & Reference to general or physical development & $\begin{array}{l}\text { Has ingredients to promote normal development. (hg) } \\
\text { It is telling me that kids can grow faster and will } \\
\text { enhance the development of kids. (hg) }\end{array}$ & 64 & 6 & 2 & 0 \\
\hline Other ingredients & $\begin{array}{l}\text { Reference to other ingredients such as } \\
\text { macronutrients (protein, fat, carbohydrates and } \\
\text { sugar), probiotics, hormones and additives }\end{array}$ & $\begin{array}{l}\text { It has added protein. (hg) Supposed to have additives } \\
\text { regular milk does not. (hg) Has antibiotics. (i) }\end{array}$ & 58 & 5 & 26 & 2 \\
\hline Bone or muscle & $\begin{array}{l}\text { Reference to bone or muscle growth or } \\
\text { development }\end{array}$ & $\begin{array}{l}\text { Helps them grow healthy bones. (hg) Build strong } \\
\text { bones and healthy muscles. (hg) }\end{array}$ & 39 & 4 & 5 & 0 \\
\hline Brain or cognition & $\begin{array}{l}\text { Reference to brain growth or development or } \\
\text { cognitive or mental development }\end{array}$ & $\begin{array}{l}\text { That the product supports brain development and } \\
\text { blood flow. (hg) Good for brain. (i) }\end{array}$ & 36 & 3 & 2 & 0 \\
\hline $\begin{array}{l}\text { Sceptical or } \\
\text { misleading }\end{array}$ & $\begin{array}{l}\text { Reference to the claim being misleading or } \\
\text { untrue or expression of scepticism about } \\
\text { the claim }\end{array}$ & More bogus advertising. (hg) False labeling. (i) & 22 & 2 & 16 & 1 \\
\hline $\begin{array}{l}\text { Immunity and illness } \\
\text { prevention }\end{array}$ & $\begin{array}{l}\text { Reference to the immune system, immunity, } \\
\text { illness, germs, defence, protection or sickness }\end{array}$ & $\begin{array}{l}\text { Helps the immune system. (hg) Protection from } \\
\text { disease causing organisms. (i) }\end{array}$ & 19 & 2 & 656 & 61 \\
\hline Meal or milk substitute & $\begin{array}{l}\text { Reference to the product being a solution to } \\
\text { picky eating or being used as a substitute for } \\
\text { regular milk, breast milk or other foods }\end{array}$ & $\begin{array}{l}\text { It gives vitamins and nutrients children might not get } \\
\text { from regular food. (hg) This product helps children's } \\
\text { immune system just like breast milk. (i) }\end{array}$ & 16 & 1 & 4 & 0 \\
\hline
\end{tabular}

hg, Quote was a response to the 'Helps Support Healthy Growth' claim.

i, Quote was a response to the 'Immunity' claim.

" $n 1074$ item wording: this product says 'Helps support healthy growth'. What does the phrase 'Helps support healthy growth' tell you about the product?

tn 1073 item wording: this product says 'Immunity'. What does the word 'Immunity' tell you about the product? 
Substitutes ${ }^{(30)}$. In addition to governmental entities, public health advocates will be key players in voicing concern about targeted marketing and putting pressure on formula companies to shift their practices ${ }^{(30)}$. For example in 2020 , a citizen's petition was filed with FDA calling for specific actions to prevent confusing or misleading toddler milk labelling and marketing ${ }^{(31)}$.

This study adds to the small existing body of research on toddler milk in the USA and provides novel information on socio-demographic characteristics associated with toddler milk perceptions and purchases. Another strength of this study is our use of a large and diverse sample. However, the use of a convenience sample may limit the external validity of our findings. Additionally, previous research has demonstrated possible confusion between toddler milk and infant formula due to similarities in product packaging $^{(13,32-34)}$, but we provided a definition of toddler milk and the intended age range for toddler milks at the beginning of the survey to minimise confusion.

\section{Conclusions}

This study provides evidence that misperceptions about toddler milk healthfulness are common among all parents, but Latinos may disproportionately purchase toddler milk. These findings can inform targeted public health interventions to improve diet quality and reduce obesity disparities in early childhood. For example, health care providers such as paediatricians and public health nutrition educators should consider providing anticipatory guidance to Latino parents about toddler milk consumption. Additionally, public health advocates should pursue efforts to reduce targeted marketing of toddler milk to Latino communities and to improve FDA regulations of claims on products intended for young children. Finally, public health researchers should use nationally representative studies such as the National Health and Nutrition Examination Survey to explore the prevalence of toddler milk consumption in the USA and if there are disparities in consumption.

\section{Acknowledgements}

Acknowledgements: N/A. Financial support: We are grateful to the Carolina Population Center for general support (P2C HD050924). The survey data used in this study were supported by a grant from Healthy Eating Research, a national programme of the Robert Wood Johnson Foundation. The views expressed here do not necessarily reflect the views of the Foundation. MGH was supported by K01HL147713 from the National Heart, Lung, and Blood Institute of the National Institutes of Health (NIH). The content is solely the responsibility of the authors and does not necessarily represent the official views of the NIH.
Conflict of interest: The authors declare that they have no competing interests. Authorship: MGH, EWD and LST led the conceptualisation and methodology of the study. MGH, LST and ICAH led the data collection. EWD led the data analysis, with contributions from LST, ICAH, APCR and MGH. All authors participated in data interpretation. EWD led original manuscript draft preparation and all authors contributed to writing and reviewing the manuscript. Ethics of buman subject participation: This study was conducted according to the guidelines laid down in the Declaration of Helsinki and all procedures involving research study participants were approved by the University of North Carolina Institutional Review Board. Written informed consent was obtained from all subjects/patients.

\section{Supplementary material}

For supplementary material accompanying this paper visit https://doi.org/10.1017/S1368980021000264

\section{References}

1. Au LE, Gurzo K, Paolicelli C et al. (2018) Diet quality of US infants and toddlers 7-24 months old in the WIC infant and toddler feeding practices study-2. J Nutr 148, 1786-1793.

2. Deming DM, Reidy KC, Briefel RR et al. (2012) The feeding infants and toddlers study (FITS) 2008: dramatic changes in the amount and quality of vegetables in the diet occur after the first year of life. FASEB J 26, 374.

3. Briefel RR, Reidy K, Karwe V et al. (2004) Toddlers' transition to table foods: impact on nutrient intakes and food patterns. J Am Diet Assoc 104, 38-44.

4. Okubo H, Crozier SR, Harvey NC et al. (2015) Diet quality across early childhood and adiposity at 6 years: the Southampton Women's Survey. Int J Obes 39, 1456-1462.

5. Skinner JD, Carruth BR, Wendy B et al. (2002) Children's food preferences: a longitudinal analysis. J Am Diet Assoc 102, 1638-1647.

6. Emmett PM \& Jones LR (2015) Diet, growth, and obesity development throughout childhood in the Avon Longitudinal Study of Parents and Children. Nutr Rev 73, 175-206.

7. Ahluwalia N (2020) Nutrition monitoring of children aged birth to 24 mo (b-24): data collection and findings from the NHANES. Adv Nutr 11, 113-127.

8. Grimes CA, Szymlek-Gay EA \& Nicklas TA (2017) Beverage consumption among US children aged 0-24 months: National Health and Nutrition Examination Survey (NHANES). Nutrients 9, 264.

9. Miles G \& Siega-Riz AM (2017) Trends in food and beverage consumption among infants and toddlers: 2005-2012. Pediatrics 139, e20163290.

10. Romo-Palafox MJ, Pomeranz JL \& Harris JL (2020) Infant formula and toddler milk marketing and caregiver's provision to young children. Matern Child Nutr 16, e12962.

11. Harris JL, Fleming-Milici F, Frazier W et al. (2017) Baby Food F.A.C.T.S: Nutrtition, Marketing of Baby, Toddler Food, Drinks. Storrs, CT: UConn Rudd Center for Food Policy \& Obesity.

12. Lott M, Callahan E, Duffy E et al. (2019) Healthy Beverage Consumption in Early Childhood: Recommendations from Key National Health and Nutrition Organizations. 
Technical Scientific Report. Durham, NC: Healthy Eating Research

13. Romo-Palafox MJ, Gershman H, Pomeranz JL et al. (2019) Marketing Claims on Infant Formula, Toddler Milk Packages: What do Caregivers Think they Mean? Storrs, CT: UConn Rudd Center for Food Policy \& Obesity.

14. Power TG, O'Connor TM, Orlet Fisher J et al. (2015) Obesity risk in children: the role of acculturation in the feeding practices and styles of low-income hispanic families. Child Obes 11, 715-721.

15. Kaiser LL, Melgar-Quiñonez HR, Lamp CL et al. (2001) Acculturation of Mexican-American mothers influences child feeding strategies. J Am Diet Assoc 101, 542-547.

16. Dancel LD, Perrin E, Yin SH et al. (2015) The relationship between acculturation and infant feeding styles in a Latino population. Obesity 23, 840-846.

17. Pérez-Escamilla R \& Putnik P (2007) The role of acculturation in nutrition, lifestyle, and incidence of type 2 diabetes among Latinos. J Nutr 137, 860-870.

18. The American Community Survey (2020) The American Community Survey 2020 Questionnaire. https://www2. census.gov/programs-surveys/acs/methodology/questionnaires/ 2020/quest20.pdf (accessed September 2020).

19. Lora KR, Davy B, Hedrick V et al. (2016) Assessing initial validity and reliability of a beverage intake questionnaire in hispanic preschool-aged children. J Acad Nutr Diet 116 1951-1960.

20. Hedrick VE, Savla J, Comber DL et al. (2012) Development of a brief questionnaire to assess habitual beverage intake (BEVQ-15): sugar-sweetened beverages and total beverage energy intake. J Acad Nutr Diet 112, 840-849.

21. Hall MG, Lazard AJ, Grummon AH et al. (2020) The impact of front-of-package claims, fruit images, and health warnings on consumers' perceptions of sugar-sweetened fruit drinks: three randomized experiments. Prev Med 132, 105998.

22. Pomeranz JL, Palafox MJR \& Harris JL (2018) Toddler drinks, formulas, and milks: labeling practices and policy implications. Prev Med 109, 11-16.

23. Ventura AK \& Mennella JA (2011) Innate and learned preferences for sweet taste during childhood. Curr Opin Clin Nutr Metab Care 14, 379-384.
24. Wills JM, genannt Bonsmann SS, Kolka M et al. (2012) European consumers, health claims: attitudes, understanding, purchasing behaviour. Proc Nutr Soc 71, 229-236.

25. Steinhauser J, Janssen M \& Hamm U (2019) Who buys products with nutrition and health claims? A purchase simulation with eye tracking on the influence of consumers' nutrition knowledge and health motivation. Nutrients 11, 2199.

26. Burton S, Cook LA, Howlett E et al. (2015) Broken halos and shattered horns: overcoming the biasing effects of prior expectations through objective information disclosure. J Acad Mark Sci 43, 240-256.

27. Food US (2013) Food and Drug Administration Center for Food Safety and Applied Nutrition. A Food Labeling Guide: Guidance for Industry. College Park, MD: Food and Drug Administration US.

28. Pomeranz JL \& Harris JL (2019) Federal regulation of infant and toddler food and drink marketing and labeling. $A m \mathrm{~J}$ Law Med 45, 32-56.

29. Center for Science in the Public Interest (2018) Re: FDA-2018N-238; The Food and Drug Administration's Comprehensive, Multi-Year Nutrition Innovation Strategy; Public Meeting; Request for Comments. https://cspinet.org/sites/default/ files/attachment/nis-cspi-comments-with-appendix_0.pdf (accessed July 2020).

30. Harris JL \& Pomeranz JL (2020) Infant formula and toddler milk marketing: opportunities to address harmful practices and improve young children's diets. Nutr Rev 78, 866-883.

31. Public Health Advocacy Institute (2020) Citizen Petition. http://uconnruddcenter.org/files/Pdfs/Full\%20Petition\% 20PHAI.pdf (accessed December 2020).

32. Cattaneo A, Pani P, Carletti C et al. (2015) Advertisements of follow-on formula and their perception by pregnant women and mothers in Italy. Arch Dis Child 100, 323-328.

33. Berry NJ, Jones SC \& Iverson D (2012) Circumventing the WHO Code? An observational study. Arch Dis Child 97, 320-325.

34. Pereira C, Ford R, Feeley AB et al. (2016) Cross-sectional survey shows that follow-up formula and growing-up milks are labelled similarly to infant formula in four low and middle income countries. Matern Child Nutr 12, 91-105. 